OPEN ACCESS

Edited by:

Gustavo Bonaventure, LemnaTec GmbH, Germany

Reviewed by: Dorothea Tholl,

Virginia Tech, United States Joaquín J. Salas,

Instituto de la Grasa (CSIC), Spain

*Correspondence:

Silke Allmann

s.allmann@uva.nl

Specialty section:

This article was submitted to

Plant Metabolism and

Chemodiversity,

a section of the journal

Frontiers in Plant Science

Received: 25 April 2017

Accepted: 18 July 2017

Published: 02 August 2017

Citation:

Spyropoulou EA, Dekker HL, Steemers $L$, van Maarseveen $J H$,

de Koster CG, Haring MA,

Schuurink RC and Allmann S (2017)

Identification and Characterization

of (3Z):(2E)-Hexenal Isomerases from

Cucumber. Front. Plant Sci. 8:1342.

doi: 10.3389/fpls.2017.01342

\section{Identification and Characterization of (3Z):(2E)-Hexenal Isomerases from Cucumber}

\author{
Eleni A. Spyropoulou', Henk L. Dekker², Luuk Steemers ${ }^{3}$, Jan H. van Maarseveen', \\ Chris G. de Koster ${ }^{2}$, Michel A. Haring ${ }^{1}$, Robert C. Schuurink ${ }^{1}$ and Silke Allmann ${ }^{1 *}$

\begin{abstract}
1 Department of Plant Physiology, Swammerdam Institute for Life Sciences, University of Amsterdam, Amsterdam, Netherlands, ${ }^{2}$ Department of Mass Spectrometry of Biomacromolecules, Swammerdam Institute for Life Sciences, University of Amsterdam, Amsterdam, Netherlands, ${ }^{3}$ Department of Synthetic Organic Chemistry, Van 't Hoff Institute for
\end{abstract} \\ Molecular Sciences, University of Amsterdam, Amsterdam, Netherlands
}

E-2-hexenal is a volatile compound that is commonly emitted by wounded or stressed plants. It belongs to the group of so-called green leaf volatiles (GLVs), which play an important role in transferring information to plants and insects. While most biosynthetic enzymes upstream of $E$-2-hexenal have been studied extensively, much less is known about the enzyme responsible for the conversion from Z-3- to E-2-hexenal. In this study we have identified two (3Z):(2E)-hexenal isomerases (HIs) from cucumber fruits by classical biochemical fractionation techniques and we were able to confirm their activity by heterologous expression. Recombinant protein of the Hls did not only convert the leaf aldehyde Z-3-hexenal to $E$-2-hexenal, but also $(Z, Z)$-3,6-nonadienal to $(E, Z)$ 2,6-nonadienal, these last two representing major flavor volatiles of cucumber fruits. Transient expression of the cucumber HIs in Nicotiana benthamiana leaves drastically changed the GLV bouquet of damaged plants from a Z-3- to an E-2-enriched GLV profile. Furthermore, transcriptional analysis revealed that the two Hls showed distinct expression patterns. While HI-1 was specifically expressed in the flesh of cucumber fruits $\mathrm{HI}-2$ was expressed in leaves as well. Interestingly, wounding of cucumber leaves caused only a slight increase in $\mathrm{HI}-2$ transcript levels. These results demonstrate that cucumber Hls are responsible for the rearrangement of Z-3-aldehydes in both leaves and fruits. Future research will reveal the physiological importance of an increased conversion to $E$-2-aldehydes for plants and insects.

Keywords: green leaf volatiles, $E-2$-hexenal, $(E, Z)-2,6-$ nonadienal, cucumber, hexenal isomerase, purification

\section{INTRODUCTION}

When plants are stressed they respond, amongst others, with the release of volatiles (Baldwin, 2010; Maffei et al., 2011; Ameye et al., 2017). This increase in plant volatiles enables them to interact with its biotic environment (Heil, 2014; Pickett and Khan, 2016). GLVs are produced by almost every plant and represent an important group of plant volatiles. While unstressed plants emit only small amounts, the release of GLVs can rapidly increase upon cell damage and other types

Abbreviations: GLVs, green leaf volatiles; HI, hexenal isomerase; HPL, hydroperoxide lyase; 13-HPOs, 13-hydroperoxides; LOX, lipoxygenase. 
of (a)biotic stresses (Scala et al., 2013a; Matsui and Koeduka, 2016). GLVs have been shown to play an important role in the activation (Bate and Rothstein, 1998; Farag and Paré, 2002; Engelberth et al., 2013) or priming (Engelberth et al., 2004; Kost and Heil, 2006; Ameye et al., 2015; Li et al., 2016) of defense responses in plants. They can influence the performance of pathogens (Shiojiri et al., 2006; Kishimoto et al., 2008; Scala et al., 2013b) and herbivores (Vancanneyt et al., 2001; Halitschke et al., 2004) and serve as infochemicals for beneficial (Turlings et al., 1991; Brodmann et al., 2008; Allmann and Baldwin, 2010) and detrimental (Halitschke et al., 2008; Li et al., 2012) insects.

Green leaf volatiles are formed via the oxylipin pathway from C18-polyunsaturated fatty acids $\alpha$-linolenic and linoleic acid (Hatanaka et al., 1987; Scala et al., 2013a; ul Hassan et al., 2015). Molecular oxygen is incorporated into free or membrane-bound fatty acids by 13-lipoxygenases and the resulting 13-hydroperoxides are cleaved through the action of HPL in a C12- (12-oxo-(Z)-9-dodecenoic acid) and a C6- ( $n$ hexanal or Z-3-hexenal) compound (Nakashima et al., 2013; Mwenda and Matsui, 2014). Z-3-hexenal, which is formed from $\alpha$-linolenic acid, can be further converted to its alcohol and esters (Bate et al., 1998; D’Auria et al., 2007; Matsui et al., 2012), but it can also rearrange either spontaneously or through catalysis by a $(3 Z):(2 E)$-hexenal isomerase $(\mathrm{HI})$ to E-2-hexenal (Allmann and Baldwin, 2010; Kunishima et al., 2016). Such isomerase activity has recently been identified in the oral secretions of the lepidopteran caterpillar Manduca sexta (Allmann and Baldwin, 2010): when feeding from their host plants, e.g., Nicotiana attenuata or Datura wrightii, their oral secretions are introduced into the leaf wounds and Z-3hexenal which is quickly formed from damaged plant material is readily converted to $E$-2-hexenal and the corresponding $E$ 2-derivatives (Allmann and Baldwin, 2010; Allmann et al., 2013). This OS-induced change in the Z-3-/E-2-ratio increased the foraging efficiency of the generalist predator Geocoris spp. (Allmann and Baldwin, 2010) and decreased the oviposition rate of female adult moths in nature (Allmann et al., 2013).

Not only insects, but also plants are able to catalyze the conversion from $Z$-3- to E-2-hexenal. Already in 1914, Curtius and Franzen isolated E-2-hexenal from $600 \mathrm{~kg}$ of common hornbeam leaves and other tree species (Curtius and Franzen, 1914). However, it took another half of a century before researchers acknowledged the involvement of an 'isomerization factor' in the rearrangement from $Z$-3- to E-2-hexenal. In these early studies increased conversion rates to $E$-2-hexenal were reported in crude extract of cucumber fruits (Galliard et al., 1976) and soybean seeds (Takamura and Gardner, 1996), in macerated tea leaves (Hatanaka and Harada, 1973) and leaves of the leopard plant Farfugium japonicum (Hatanaka et al., 1976). HI activity has been partially purified from Alfalfa seedlings and cucumber fruits (Phillips et al., 1979; Noordermeer et al., 1999), but only very recently the gene responsible for the conversion from $Z$ 3- to $E$-2-hexenal has been identified from red bell pepper fruits (Kunishima et al., 2016).

Here, we purified HI activity from cucumber fruits and identified the corresponding gene responsible for the rearrangement from $Z$-3- to $E$-2-hexenal. We identified in total four putative homologs in cucumber of which two possessed HI activity when expressed in Escherichia coli or transiently expressed in Nicotiana benthamiana. We furthermore identified tissue-specific expression patterns of the four putative homologs, tested wound-inducibility of the leaf-specific $\mathrm{HI}$ and determined kinetic parameters of the recombinant proteins of the two active cucumber HI homologs.

\section{MATERIALS AND METHODS}

\section{Plant Material and Growing Conditions}

Cucumber seeds (Cucumis sativus, var. Kurios; E 31.2148) were kindly provided by Enza Zaden (Enkhuizen, $\mathrm{NL}^{1}$ ) and grown in the glasshouse with day/night temperatures of $23 / 18^{\circ} \mathrm{C}$ and a 16/8 h light/dark regime for 9-12 weeks. $N$. benthamiana plants were grown in the glasshouse for 3 weeks and then transferred to a climate room $\left(25^{\circ} \mathrm{C}, 16 / 8 \mathrm{~h}\right.$ light/dark, $70 \%$ humidity).

\section{Isomerase Activity Assays}

Enzyme activity was determined by SPME-GC-ToF-MS or SPME-GC-QToF-MS. $200 \mu \mathrm{L}$ of solution, either containing crude extract, purified fractions or purified recombinant proteins, were transferred to a $1.5 \mathrm{~mL}$ GC vial equipped with a $200 \mu \mathrm{L}$ insert, and $Z$-3-hexenal in different concentrations was added to the solution. A volume of $200 \mu \mathrm{L}$ was chosen to minimize the headspace and thus also the chance of $Z$ 3-hexenal to volatilize. The GC vial was closed and gently shaken for $2 \mathrm{~min}$ (recombinant protein) or $5 \mathrm{~min}$ (collected fractions from partial purification). Subsequently, the liquid solution was transferred to a $20 \mathrm{~mL}$ SPME vial which was immediately closed with a Teflon lined crimp cap and incubated under moderate shaking for 1 or $5 \mathrm{~min}$ at $35^{\circ} \mathrm{C}$ prior to sampling.

\section{Analysis of Volatiles}

Volatiles were initially analyzed by GC-ToF-MS (samples from the purification), until we obtained a new more sensitive GCQTof-MS. In all cases volatiles were sampled with a Solid Phase Micro Extraction fiber (SPME; Carboxem/PDMS) for $10 \mathrm{~min}$ at $35^{\circ} \mathrm{C}$.

\section{Analysis of Volatiles by GC-ToF-Ms}

After sampling for $10 \mathrm{~min}$ the fiber was desorbed for $1 \mathrm{~min}$ in an Optic injector port (ATAS GL Int., Zoeterwoude, NL) which was constantly kept at $250^{\circ} \mathrm{C}$. Compounds were separated on a DB-5 column $(10 \mathrm{~m} \times 180 \mu \mathrm{m}, 0.18 \mu \mathrm{m}$ film thickness; Hewlett Packard) in a $6890 \mathrm{~N}$ gas chromatograph (Agilent, Amstelveen, NL) with a temperature program set to $40^{\circ} \mathrm{C}$ for $1.5 \mathrm{~min}$, increasing to $250^{\circ} \mathrm{C}$ at $30^{\circ} \mathrm{C}$ per min and $250^{\circ} \mathrm{C}$ for an additional $2.5 \mathrm{~min}$. Helium was used as carrier gas, with the transfer column flow set to $3 \mathrm{~mL}$ per minute for $2 \mathrm{~min}$, and to $1.5 \mathrm{~mL}$ per minute thereafter. Mass spectra were generated

\footnotetext{
${ }^{1}$ http://www.enzazaden.nl/
} 
by electron ionization with $70 \mathrm{eV}$ electrons at $200^{\circ} \mathrm{C}$ and collected with a Time-of-Flight MS (Leco, Pegasus III, St. Joseph, MI, United States), with an acquisition rate of 20 scans per second.

\section{Analysis of Volatiles by GC-QToF-Ms}

After sampling for $10 \mathrm{~min}$ the fiber was desorbed for $1 \mathrm{~min}$ in the injection port which was constantly kept at $250^{\circ} \mathrm{C}$. Compounds were separated on HP-5 ms column $(30 \mathrm{~m} \times 250 \mu \mathrm{m}$, $0.25 \mu \mathrm{m}$ film thickness; Agilent) in an Agilent $7890 \mathrm{~A}$ gas chromatograph with a temperature program set to $40^{\circ} \mathrm{C}$ for $5 \mathrm{~min}$, increasing to $140^{\circ} \mathrm{C}$ at a rate of $5^{\circ} \mathrm{C}$ per min, followed by increasing temperature to $250^{\circ} \mathrm{C}$ at a rate of $15^{\circ} \mathrm{C}$ per $\min$ and an additional $5 \mathrm{~min}$ at $250^{\circ} \mathrm{C}$. Helium was used as the carrier gas with the transfer column flow set to $3 \mathrm{~mL}$ per minute and a flow rate of $1 \mathrm{~mL}$ per $\mathrm{min}$ thereafter. Mass spectra were generated by an Agilent 7200 accurate-mass quadrupole time-of-flight mass spectrometer, operating in electron ionization mode $(70 \mathrm{eV})$ at $230^{\circ} \mathrm{C}$ and collected with an acquisition rate of 20 scans per second. volatiles were identified and quantified using standard solutions of Z-3-hexenal, Z-3-hexenol, E-2-hexenal, E-2-hexenol and (E,Z)-2,6-nonadienal (Sigma-Aldrich). (Z,Z)-3,6-nonadienal was synthesized from $(Z, Z)-3,6$-nonadienol (Ventos) as described below.

\section{Purification of (3Z):(2E)-Hexenal Isomerase Activity from Cucumber Fruits}

All procedures (except for the FPLC runs at RT) were performed at $4^{\circ} \mathrm{C}$.

Step 1: Preparation of crude extract. Two cucumber fruits were pealed and mixed in a blender. The crude extract was filtered through cheesecloth and Miracloth and subsequently diluted in $1 / 2$ volume of buffer ( $20 \mathrm{mM}$ MOPS $\mathrm{pH} 7.5,0.2 \%$ Tween$20,10 \mathrm{mM}$ DTT). The solution was centrifuged at $10,000 \mathrm{~g}$ for $40 \mathrm{~min}$ at $4^{\circ} \mathrm{C}$ and the crude supernatant was pushed through a $0.45 \mu \mathrm{m}$ filter, transferred to a new tube and stored at $4^{\circ} \mathrm{C}$ overnight.

Step 2. Batch assay, cation exchange. The crude supernatant $(240 \mathrm{~mL})$ was added to $1.5 \mathrm{~g}$ of carboxy methyl (CM) Sephadex C-25, which had been equilibrated in $50 \mathrm{~mL}$ MOPS $(20 \mathrm{mM}$ $\mathrm{pH} 7.5,0.2 \%$ Tween-20) overnight. The suspension was gently shaken for $30 \mathrm{~min}$ at $4^{\circ} \mathrm{C}$ and centrifuged at 9,000 $\mathrm{g}$ for $25 \mathrm{~min}$ at $4^{\circ} \mathrm{C}$. The supernatant was collected and tested for isomerase activity. The CM Sephadex pellet was resuspended in $200 \mathrm{~mL}$ of $200 \mathrm{mM} \mathrm{NaCl}$ and left on ice for $2 \mathrm{~h}$. This solution was centrifuged at $9,000 \mathrm{~g}$ for $25 \mathrm{~min}$ at $4^{\circ} \mathrm{C}$ and the supernatant was collected and subsequently tested for isomerase activity. All isomerase activity was found in the (unbound) supernatant of the CM Sephadex.

Step 3. Anion exchange chromatography. To remove small particles we pushed the isomerase containing solution through a $0.22 \mu \mathrm{m}$ filter and applied the filtered solution to a HiPrepQ XL 16/10 column (GE Healthcare) which had been equilibrated with starting buffer (50 mM MOPS pH 7.5). The adsorbed proteins were eluted with an increasing linear gradient of
$\mathrm{NaCl}$ in the same buffer $[0-1 \mathrm{M} \mathrm{NaCl}$ in 10 column volumes $(\mathrm{CVs})]$ and a constant flow of $5 \mathrm{~mL} / \mathrm{min}$. Pools of 5 fractions ( $5 \mathrm{ml} /$ fraction) were tested for isomerase activity. All active fractions were snap frozen and stored at $-80^{\circ} \mathrm{C}$.

Step 4. Hydrophobic interaction chromatography. The active fractions were pooled (6-20, approximately $67.5 \mathrm{~mL}$; Supplementary Figure S1), diluted with $22.5 \mathrm{~mL}$ of $4 \mathrm{M}$ $\left(\mathrm{NH}_{4}\right)_{2} \mathrm{SO}_{4}$ and filtered $(0.22 \mu \mathrm{m}$ pore size $)$. The filtered solution was applied to a HiPrep Phenyl HP 16/10 column which had been equilibrated with starting buffer $[1 \mathrm{M}$ $\left(\mathrm{NH}_{4}\right)_{2} \mathrm{SO}_{4}, 50 \mathrm{mM}$ MOPS $\mathrm{pH}$ 7.5]. The adsorbed proteins were eluted with a linear gradient from 1 to $0 \mathrm{M}\left(\mathrm{NH}_{4}\right)_{2} \mathrm{SO}_{4}$ in $50 \mathrm{mM}$ MOPS pH 7.5 and a constant flow of $3 \mathrm{ml} / \mathrm{min}$ in 10 CVs. The active fractions (27-36, Supplementary Figure S1) were pooled and an equivalent of $50 \mu \mathrm{g}$ of total protein was precipitated with $80 \%$ acetone. Two non-active fractions (13 and 14, Supplementary Figure S1) were taken along as negative controls. The precipitated pellets were re-suspended in $0.1 \mathrm{M}$ Tris $\mathrm{pH} 7.6$ in the same starting sample volume and used for SDS-PAGE and analysis with LC-MS [Supplementary Figure S1, Step 5; see below (Mass spectrometry analysis and identification) for details].

Step 6. Gel filtration. Since the above-mentioned purification steps did not suffice to identify a cucumber hexenal isomerase (Supplementary Table S1) we used $10 \mathrm{~mL}$ of the pooled active fractions (from step 4, Supplementary Figure S1), which had not been precipitated, for additional purification. The pooled active fractions were diluted in $0.5 \mathrm{~mL} 3 \mathrm{M} \mathrm{NaCl}$ and filter sterilized $(0.22 \mu \mathrm{m}$ pore size $)$. The filtered solution was applied to a gel filtration column (Sephacryl S-300 High resolution, HiPrep 26/60; GE Healthcare) that had been equilibrated with buffer (50 mM MOPS, pH 7.5, 0.15 M NaCl). The column was run with a constant flow of $1.3 \mathrm{~mL} / \mathrm{min}$. Single fractions or a pool of fractions were tested for isomerase activity. All fractions were snap frozen and stored at $-80^{\circ} \mathrm{C}$.

Step 7. Hydrophobic interaction chromatography. The active fractions (10-12, Supplementary Figure S2) were pooled and the total of $15.75 \mathrm{~mL}$ was diluted with $5.25 \mathrm{~mL} 4 \mathrm{M}\left(\mathrm{NH}_{4}\right)_{2} \mathrm{SO}_{4}$ and filtered $(0.22 \mu \mathrm{m}$ pore size). The filtered solution was applied to a HiTrap Phenyl HP (5 mL; GE Healthcare) column which had been equilibrated with starting buffer [1 $\mathrm{M}\left(\mathrm{NH}_{4}\right)_{2} \mathrm{SO}_{4}, 50 \mathrm{mM}$ MOPS $\mathrm{pH}$ 7.5]. The adsorbed proteins were eluted with a linear gradient from 1 to $0 \mathrm{M}$ $\left(\mathrm{NH}_{4}\right)_{2} \mathrm{SO}_{4}$ in $50 \mathrm{mM}$ MOPS pH 7.5 and a constant flow of $3 \mathrm{ml} / \mathrm{min}$ in $10 \mathrm{CVs}$. Single fractions or a pool of fractions were tested for isomerase activity. Two $\mathrm{mL}$ of the active fractions (31-32, Supplementary Figure S2) and a pooled non-active fraction (28-30) were analyzed by LC-MS. All fractionations were performed with a FPLC (AKTA; GE healthcare) and protein elution was continuously monitored by UV absorption at $280 \mathrm{~nm}$. Protein concentrations for step 1 till 4 were determined by Bradford assay using BSA for quantification. Because of the low protein concentrations after steps 6 and 7, we estimated the amount of total protein using $1 \mathrm{~A}_{280}=1 \mathrm{mg} / \mathrm{mL}$. Peak areas for this calculation were determined with ImageJ $1.50 \mathrm{i}$ using the original chromatograms of Supplementary Figure S2. 


\section{Mass Spectrometric Analysis and Identification}

\section{Sample Handling Active versus Non-active Fractions}

For the first comparative analysis (Purification part I, Supplementary Figure S1) about $3 \mu \mathrm{g}$ of protein material from the pooled active and a non-active fraction were separated on $10 \%$ SDS-PAGE. No staining was used and the individual lanes were cut in 10 separate gel pieces from top to bottom. Each gel piece was digested in-gel with trypsin based on the method according to Shevchenko et al. (1996). The collected eluates after two separate $30 \mathrm{~min}$ extractions with $10 \mathrm{mM} \mathrm{NH}_{4} \mathrm{HCO}_{3}$ and one with $50 \%$ acetonitrile were freeze dried. The peptides were reconstituted in $20 \mu \mathrm{L} 50 \%$ acetonitrile (ACN), $2 \%$ formic acid and stored at $-20^{\circ} \mathrm{C}$ prior to analysis with LC-MS.

For the second comparison (Purification part II, Supplementary Figure S2) the liquid fractions were digested in solution according to an in-house trypsin based protocol. Alkylation before overnight digestion was done with iodoacetamide and a final concentration of $10 \%$ ACN was used to support the trypsin digestion. Digestion was stopped by adding trifluoric acid (TFA) with a final concentration of $1 \%$ and the sample was diluted to $3 \%$ acetonitrile. The peptides were collected by using a $2 \mu \mathrm{g}$ capacity C18 ZipTips (Millipore) and the eluted peptides had a final volume of $10 \mu \mathrm{L} 50 \% \mathrm{ACN}, 0.1 \%$ TFA and were stored at $-20^{\circ} \mathrm{C}$ before analysis with LC-MS.

\section{Mass Spectrometric Analysis}

An AmaZon Speed Iontrap MS/MS with a CaptiveSpray ion source (Bruker) coupled to an EASY-nLC II (Proxeon, Thermo Scientific) chromatographic system was used for the analysis. A fraction of the stored sample was dried in a speedvac and reconstituted in $6 \mu \mathrm{L} 2 \% \mathrm{ACN}, 0.1 \%$ TFA. Peptide samples were injected with a sample volume of $5 \mu \mathrm{L}$ (Purification part I, Supplementary Table S1), $2 \mu \mathrm{L}$ (Purification part II, Run 1, Supplementary Table S2) or $8 \mu \mathrm{L}$ (Run 2, Supplementary Table S2) and separated with an eluent flow of $300 \mathrm{~nL} \mathrm{~min}{ }^{-1}$ on an Acclaim PepMap100 (C18 $75 \mu \mathrm{M} 25 \mathrm{~cm}$ Dionex, Thermo Scientific) analytical column combined with an Acclaim PepMap100 pre-column (C18 $100 \mu \mathrm{M} 2 \mathrm{~cm}$ Dionex, Thermo Scientific) using a $30 \mathrm{~min}$ gradient of $0-50 \% \mathrm{ACN}$ and $0.1 \%$ formic acid. Peptide precursor ions above a predefined threshold ion count were selected for low-energy collision-induced dissociation (CID) to obtain fragmentation spectra of the peptides. After processing the raw data with Data Analysis software (Bruker), the resulting mgf datafiles were used for database searching with Mascot software (Version 2.5.1) in an online available database of C. sativus (Csativus_122_protein.fa.gz; Phytozome v9.0 ${ }^{2}$ ). Searches were simultaneously performed against a "common contaminants database"3 (compiled by Max Planck Institute of Biochemistry, Martinsried, Germany) to minimize false identifications. Mascot search parameters were a fixed modification of carbamidomethyl for cysteine, variable modification of oxidized methionine and trypsin with the allowance of one missed cleavage and peptide

${ }^{2}$ https://phytozome.jgi.doe.gov/pz/portal.html

${ }^{3}$ http://www.matrixscience.com/help/seq_db_setup_contaminants.html charge state $+2,+3$, and +4 . Peptide and MS/MS mass error tolerances were $0.3 \mathrm{Da}$ for ESI-Trap.

\section{Cloning and Construct Design}

The cDNA sequences of Cucumber Cs033080, Cs033090, Cs078390, Cs240840, and Cs387820 were obtained from Phytozome ${ }^{2}$ (accession numbers: Cucsa.033080.1, Cucsa.033090.1, Cucsa.078390.1, Cucsa.240840.1 and Cucsa.387820.1, Supplementary Table S3). The ORFs of four candidates were cloned from a mix of cucumber leaf, tendril, and petiole cDNA in the pJET1.2/blunt vector (Thermo Fisher) and verified by sequencing. Unfortunately we were unable to clone candidate Cs387820. Primers containing the attB1 and attB2 Gateway recombination sites were used to amplify all ORF sequences. The resulting PCR products were recombined with the Gateway vector pDONR207 (Clontech) using BP Clonase II (Thermo Fisher). All constructs were verified by PCR and sequencing prior to LR-reaction with the destination vector. For the transient assay in $N$. benthamiana leaves the cDNA clones were introduced into the destination vector pK2GW7 under control of the $35 \mathrm{~S}$ CaMV promoter ${ }^{4}$. For expression of recombinant protein in $E$ coli the cDNA clones were introduced into the destination vector pGEX-KG-GW (Dhonukshe et al., 2010). LR reactions were performed with LR Clonase II (Thermo Fisher) and the resulting clones were confirmed by PCR and sequencing.

\section{Transient Expression of Protein in Nicotiana benthamiana Leaves}

Agro-infiltrations were performed with 4 week-old $N$. benthamiana plants. Agrobacterium tumefaciens GV3101 (pMP90) cultures carrying the HI-candidate constructs (pK2GW7: 35S-Cs033090, 35S-Cs033080, 35S-Cs240840, 35S-Cs078390) or a construct carrying only GFP (pK7WGF2.0) (Karimi et al., 2005) were grown overnight from a single colony and diluted in infiltration buffer $[1 / 4(\mathrm{v} / \mathrm{v})$ LB medium, $1 / 4(\mathrm{v} / \mathrm{v})$ sterile $\mathrm{H}_{2} \mathrm{O}, 1 / 2(\mathrm{v} / \mathrm{v}) 2 \mathrm{x}$ MS medium in $10 \mathrm{mM}$ MES $\mathrm{pH}$ 5.6, $20 \mathrm{mM}$ glucose, $10 \%$ (w/v) sucrose, and $200 \mu \mathrm{M}$ acetosyringone] to an $\mathrm{OD}_{600}$ of 0.6. To suppress gene silencing each construct was co-infiltrated in a 1:1 ratio with an A. tumefaciens GV3101 (pMP90) strain that carried the pBIN61 vector to express the P19 suppressor (Voinnet et al., 2003). Six leaves of three plants were infiltrated for each HI-construct. Different areas of each leaf were infiltrated with two control samples [infiltration buffer and 35S-GFP (pK7WGF2.0)] and one of the HI-constructs. Five, six and seven days after infiltration leaf disks with a diameter of $2 \mathrm{~cm}$ were sequentially collected per plant for each infiltration area, and leaf material per plant and construct was pooled prior to analysis. The collected leaf disks were immediately wounded five times with a riffled forceps and placed in a $20 \mathrm{~mL}$ SPME vial which was immediately closed with a Teflon lined crimp cap and measured with GC-QToF-MS. Volatiles were sampled with a Solid Phase Micro Extraction fiber (SPME; Carboxem/PDMS) for $10 \mathrm{~min}$ at $35^{\circ} \mathrm{C}$ and volatiles were analyzed as described above. Since it was impossible to measure all samples on

${ }^{4}$ http://www.vib.be 
1 day we measured biological replicates on three consecutive days.

\section{Production of Recombinant Protein}

For the production of recombinant protein the constructs were transformed into E. coli C41 (DE3) cells. A single colony was inoculated in 2-YT medium (Tryptone $16 \mathrm{~g} / \mathrm{l}$, Yeast extract $10 \mathrm{~g} / \mathrm{l}, \mathrm{NaCl} 5 \mathrm{~g} / \mathrm{l})$. The next day, the culture was diluted 1:30 in $150 \mathrm{~mL}$ of 2-YT medium and grown at $37^{\circ} \mathrm{C}$ until an $\mathrm{OD}_{600}$ of approximately 0.9 . Protein expression was induced with $1 \mathrm{mM}$ Isopropyl- $\beta$-D-thiogalactoside and the cultures were incubated at $20^{\circ} \mathrm{C}$ for $22 \mathrm{~h}$ with $200 \mathrm{rpm}$ agitation. Cells were harvested by centrifugation at 5,000 $\mathrm{g}$ for $15 \mathrm{~min}$ and pellets were snap frozen in liquid nitrogen, and stored at $-80^{\circ} \mathrm{C}$. The harvested cells were re-suspended in extraction buffer [20 mM Tris buffer ( $\mathrm{pH} 7.5), 100 \mathrm{mM}$ $\mathrm{NaCl}, 5 \mathrm{mM}$ EDTA, $1 \mathrm{mM}$ EGTA, $5 \mathrm{mM}$ DTT] containing lysozyme $(1 \mathrm{mg} / \mathrm{mL})$ and $10 \mathrm{mM}$ Complete Protease Inhibitor Cocktail (Roche Amersham). Cells were incubated on ice for $30 \mathrm{~min}$ and subsequently lysed by sonicating six times for each $20 \mathrm{~s}$, and crude protein extracts were centrifuged at $10,000 \mathrm{~g}$ for $15 \mathrm{~min}$. Five $\mathrm{mL}$ of the supernatant was pushed through a $0.22 \mu \mathrm{m}$ filter and the filtered solution was applied to a $1 \mathrm{~mL}$ GSTrap FF column (GE Healthcare) which had been equilibrated with starting buffer (1x PBS). The flow rate was kept at $0.2 \mathrm{~mL} / \mathrm{min}$ during sample loading and was increased to $1 \mathrm{~mL} / \mathrm{min}$ afterward. Proteins were eluted stepwise with elution buffer $(50 \mathrm{mM}$ Tris- $\mathrm{HCl} \mathrm{pH} 8$, $10 \mathrm{mM}$ reduced glutathione, $10 \mathrm{mM}$ Complete Protease Inhibitor Cocktail), which was continuously monitored by UV absorption at $280 \mathrm{~nm}$. Purified recombinant proteins (Supplementary Figure S5) were tested for isomerase activity, $10 \%$ glycerol was added to the protein and aliquots were snap-frozen at $-80^{\circ} \mathrm{C}$.

\section{Kinetics}

In order to determine the kinetic parameters of the two active HIs, Cs033090 and Cs078390, purified GST-tagged proteins were used (see above for details of the assay). Purified GSTtagged protein $(\sim 63 \mathrm{kDa} ; 6 \mathrm{ng}$ for 033090 and $420 \mathrm{ng}$ for 078390) was diluted in reaction buffer [10 mM MOPS, $\mathrm{pH} 7.5,2 \mu \mathrm{L}$ BSA $(10 \mathrm{mg} / \mathrm{mL})$ ] to a final volume of $200 \mu \mathrm{L}$. The substrate $Z$-3-hexenal was added to the reaction mixture in a concentration range of $100-2500 \mu \mathrm{M}$ and the mixture was incubated for $2 \mathrm{~min}$ at RT while gently shaking. To stay within the linear range of the instrument (GCQToF-MS) an aliquot (4-100 $\mu \mathrm{L})$ of the reaction mixture containing an equivalent of $50 \mu \mathrm{M} \mathrm{Z}$-3-hexenal was transferred to a $20 \mathrm{~mL}$ SPME vial, immediately closed and volatiles were absorbed onto the fiber for $10 \mathrm{~min}$. The fiber was subsequently injected into the GC and volatiles were analyzed as described above. To determine the conversion from $Z$ 3-hexenal to $E$-2-hexenal we first calculated the sum of aldehydes (Z-3-hexenal $+E$-2-hexenal) measured by SPME, taking the response factors of each compound into account. We subsequently calculated the percentage of E-2-hexenal and subtracted the non-enzymatic conversion from this value.
Final concentrations of E-2-hexenal were then re-calculated by taking the initial concentration of Z-3-hexenal used for the assay into account. $\mathrm{K}_{\mathrm{m}}$ and $\mathrm{K}_{\text {cat }}$ values were determined from Lineweaver-Burk Plots $(n=3$ for HI-1, $n=4$ for HI-2).

\section{$(Z, Z)-3,6-$ Nonadienal Synthesis and Substrate Testing}

The aldehyde $(Z, Z)-3,6$-nonadienal was synthesized from $(Z, Z)$ 3,6-nonadienol (Ventos, ${ }^{5}$ Barcelona, Spain) by oxidation with $o$-iodoxybenzoic acid as described in Sasaki et al. (2011). To test whether the two active HIs, Cs033090 and Cs078390, are able to use also $(Z, Z)-3,6$-nonadienal as substrate we measured the conversion of $(Z, Z)-3,6$-nonadienal to $(E, Z)-2,6$-nonadienal by SPME-GC-QToF-MS as described above using $2 \mu \mathrm{g}$ of purified GST-tagged protein.

\section{Quantitative Real-Time PCR}

For tissue-specific expression analysis we harvested material from three 9 week-old cucumber plants. We used the third youngest leaf [leaf; Figure 5 (c)] and its petiole [petiole (d)], the tendrils of the three youngest leaves [tendril (e)] and two fruits per plant, which were pealed to separately test skin and pealed fruit [fruit (a) and skin (b)]. Plant material was flash frozen in liquid nitrogen and stored at $-80^{\circ} \mathrm{C}$ until use.

For the time-course experiment we used four plants per time point. The first fully expanded true leaf of 2 week-old cucumber plants was wounded with a pattern wheel to punch five rows of holes on each side of the midrib. After the indicated time (between $30 \mathrm{~min}$ and $6 \mathrm{~h}$ ) the treated leaves were harvested, flash frozen in liquid nitrogen and stored at $-80^{\circ} \mathrm{C}$ until use. Samples from untreated plants were used as controls.

Total RNA was extracted from ground plant material using TRIzol Reagent (Thermo Fisher) according to the manufacturer's protocol, and DNase treated (TURBO DNase kit, Ambion). cDNA was synthesized from $1 \mu \mathrm{g}$ of total RNA using the RevertAid kit (Fermentas). Quantitative real-time PCR (ABI 7500 Real-Time PCR System; Applied Biosystems) was done with cDNA equivalents of $10 \mathrm{ng}$ total RNA using the EVAGreen Real-Time PCR Mastermix (Biotium) and gene-specific primers (Supplementary Table S4). Specificity was verified by dissociation analysis and expression of cucumber Actin-like7 gene was used for normalization (Shi et al., 2015). Primer efficiencies were calculated by analysis of amplification curves of a cDNA dilution range. Three to four biological replicates were analyzed individually.

\section{Statistical Analysis}

Statistics were done with IBM SPSS Statistics 22. Data were compared using analysis of variance (ANOVA) followed by a Scheffé post hoc test.

\footnotetext{
${ }^{5}$ https://www.ventos.com
} 


\section{RESULTS}

\section{Purification of a (3Z):(2E)-Hexenal Isomerase from Cucumber Fruits}

(3Z):(2E)-hexenal isomerase activity has been described for several plant species (Phillips et al., 1979; Takamura and
Gardner, 1996; Noordermeer et al., 1999), but the underlying gene responsible for the conversion from Z-3-hexenal to E-2hexenal had, until recently (Kunishima et al., 2016), not been identified. In order to identify such hexenal isomerase (HI) we purified proteins from pealed cucumber fruits and used a GC-MS based assay to drive the fractionation of enzymatic

TABLE 1 | Summary of (3Z):(2E)-hexenal isomerase purification from cucumber fruits ${ }^{\mathrm{a}}$.

\begin{tabular}{|c|c|c|c|c|c|c|}
\hline Step & Description & Total protein $(\mathrm{mg})$ & Total activity (units) ${ }^{\mathrm{c}}$ & Specific activity (units/mg) & Purification (fold) & Yield (\%) \\
\hline 1 & Crude extract & $56.2^{\mathrm{b}}$ & 2103.9 & 37.4 & 1.0 & 100 \\
\hline 2 & CM-Sephadex & $45.9^{b}$ & 992.5 & 21.6 & 0.6 & 47.2 \\
\hline 4 & Phenyl Sepharose column & $4.9^{b}$ & 458.5 & 93.8 & 2.5 & 21.8 \\
\hline 6 & Sephacryl S-300 column & $0.04^{d}$ & 86.9 & 2421 & 64.7 & 4.1 \\
\hline 7 & Phenyl-Sepharose column & $0.0006^{d}$ & 24.2 & 43472 & 1161 & 1.2 \\
\hline
\end{tabular}

aDetailed information about the purification steps can be found in Supplementary Figures S1, S2.

${ }^{\mathrm{b}}$ Protein concentration determined by Bradford assay using BSA as standard.

c 1 unit causes $50 \%$ conversion to E-2-hexenal in 5 min.

dProtein concentration was estimated using $1 A_{280}=1 \mathrm{mg} / \mathrm{mL}$.

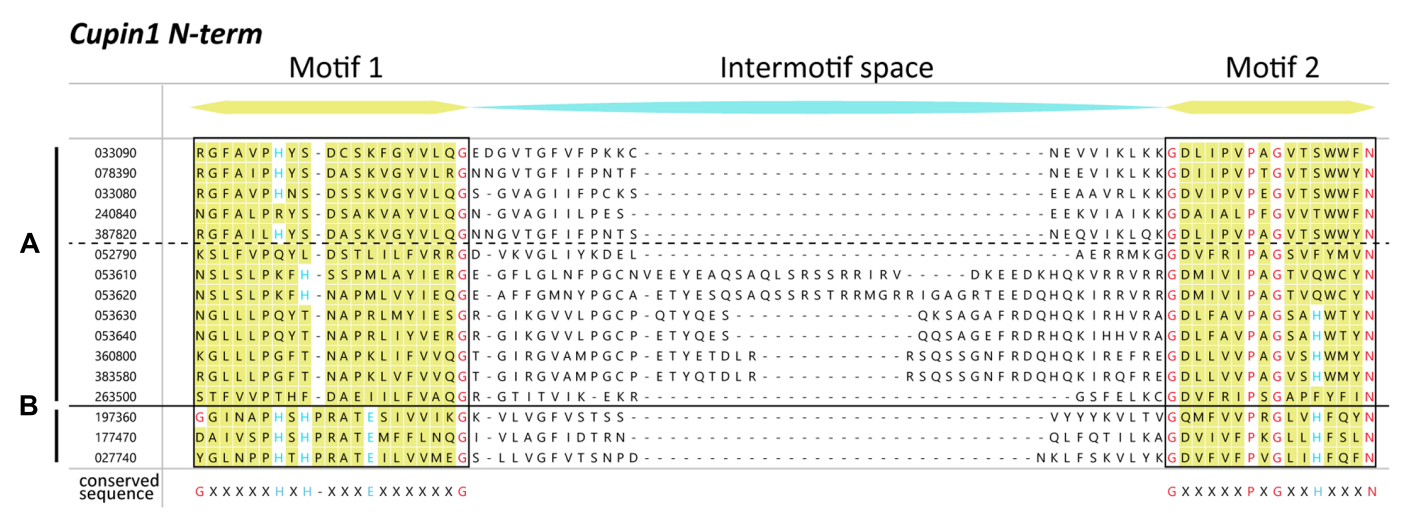

\section{Cupin1 C-term}

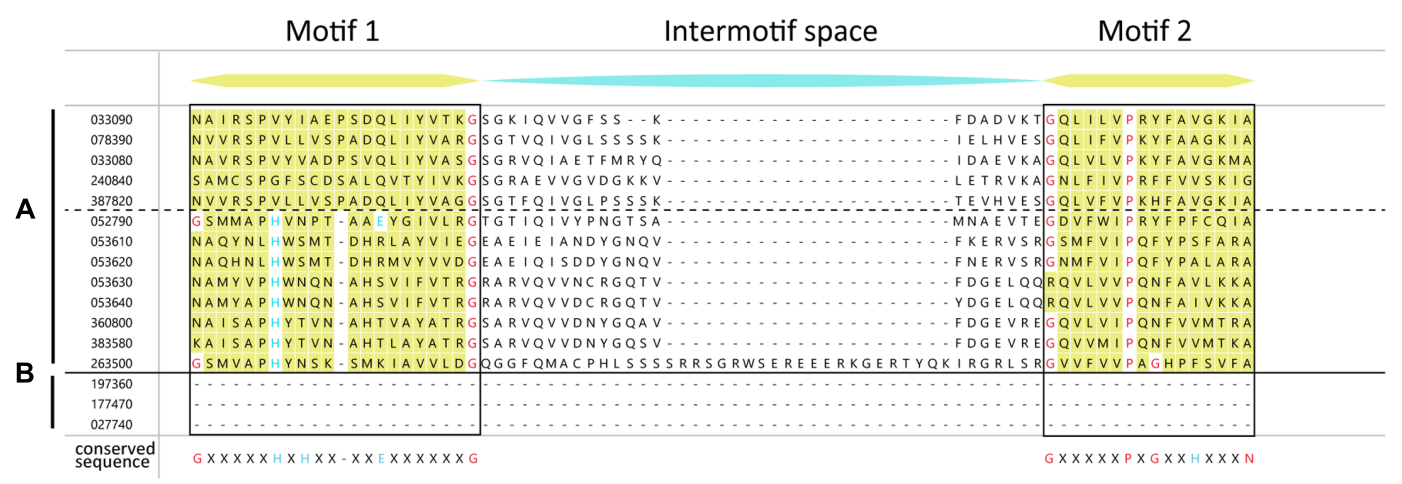

FIGURE 1 | Multiple sequence alignment of the two conserved motifs of putative cupin proteins from cucumber containing a Pfam00190 (cupin1) family. The two conserved motifs of cupins are denoted in yellow, with highly conserved residues in red (conserved structurally important residues) and blue (conserved active-site residues). Sequences above the dotted line are proposed to be homologs of Cs033090, the putative hexenal isomerase. The sequences are divided according to the number of cupin domains [one cupin domain $(B)$; two cupin domains $(A)$ ]. The conserved sequence for each motif is given below the alignment [motif 1 : $\mathrm{G}(\mathrm{x})_{5} \mathrm{HxH}(\mathrm{x})_{3,4} \mathrm{E}(\mathrm{x})_{6} \mathrm{G}$; motif 2: $\left.\mathrm{G}(\mathrm{x})_{5} \mathrm{PxG}(\mathrm{x})_{2} \mathrm{H}(\mathrm{x})_{3} \mathrm{~N}\right]$. Cucumber sequences with a Pfam00190 were retrieved from Phytozome and incomplete sequences (two sequences) were removed prior to analysis. Alignment was done with MegAlign Pro using the clustal omega algorithm with default settings. $\mathrm{N}$-term, $\mathrm{N}$-terminal; C-term, C-terminal. 
activity. Crude cucumber extract was sequentially fractionated by cation exchange, anion exchange, and hydrophobic interaction chromatography (HIC; Supplementary Figure S1). However, the purification steps only led to a moderate increase in specific activity (Table 1). This was reflected by the high number of possible candidates identified by LC-MS/MS from in-gel trypsindigested slices of pooled active and non-active fractions that had been separated on SDS-PAGE (Supplementary Figure S3). Since our purification strategy did not suffice to identify a cucumber HI (Supplementary Table S1) we proceeded with the purification.

Pooled active fractions were sequentially fractionated on gel filtration and HIC columns (Supplementary Figure S2). This procedure overall led to a 1161 -fold purification with a $1.2 \%$ recovery (yield; Table 1). The pooled final active (31 and 32) and non-active (27-29) fractions were digested with trypsin and analyzed by LC-MS/MS, which resulted in a list of candidate proteins that were either enriched or solely present in the active fraction (Supplementary Table S2). While the two most abundant proteins identified from the active fractions, arginase (Cs362680) and protein-disulfide isomerase (Cs188190), are well-described enzymes involved in the release of nitrogen from arginine (Chen et al., 2004) and the correct folding of proteins (Cho et al., 2011), respectively, the third most abundant candidate, Cs033090, was assigned as a cupin-like protein. This candidate gave a very high protein coverage score (Supplementary Table S2 and Figure S4; $59 \%$ AA coverage) and was clearly enriched in the active fractions of both runs compared to the non-active fractions (Run II: protein score of 1302 versus 35 ).

\section{The (3Z):(2E)-Hexenal Isomerase Is a Cupin-Like Protein}

The superfamily of cupins is a functionally very diverse group of proteins with a putative $\beta$-barrel shape. The family consists of enzymatic and non-enzymatic members with either one, two, or even more cupin domains which have been described for prokaryotes as well as eukaryotes (Dunwell et al., 2004). The main characteristic of the cupin domain is a two-motif structure

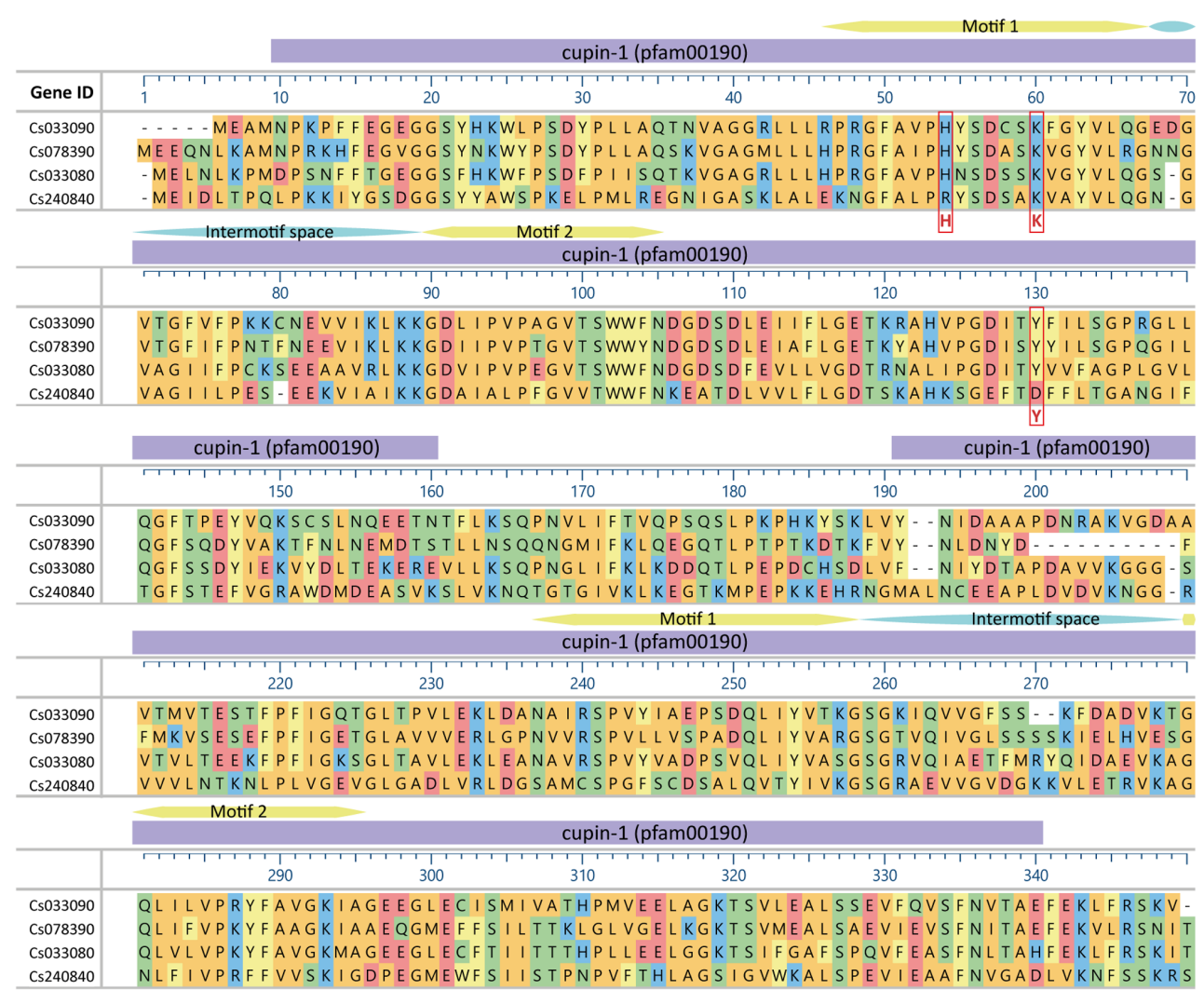

\begin{tabular}{|c|c|}
\hline & $\begin{array}{llll}\pi & 1 \\
& 160\end{array}$ \\
\hline Cs033090 & $\ldots \ldots \ldots$ \\
\hline Cs078390 & $N \ldots \ldots$ \\
\hline Cs033080 & KSSPLVPPSDS \\
\hline Cs240840 & SDA IFFPPSN- \\
\hline
\end{tabular}

FIGURE 2 | Alignment of hexenal isomerase (HI) proteins from cucumber. The position of amino acids HKY of the catalytic site according to Kunishima et al. (2016) are marked with a red box. Conserved domains are indicated on top as purple bars, conserved motifs and interspace motifs in yellow and blue, respectively. Amino acids are colored according to their side chain chemistry. Alignment was done with MegAlign Pro using the clustal omega algorithm with default settings. 
consisting of conserved motif $1\left[\mathrm{G}(\mathrm{X})_{5} \mathrm{HXH}(\mathrm{X})_{3}{ }_{4} \mathrm{E}(\mathrm{X})_{6} \mathrm{G}\right]$ and conserved motif $2\left[\mathrm{G}(\mathrm{X})_{5} \mathrm{PXG}(\mathrm{X})_{2} \mathrm{H}(\mathrm{X})_{3} \mathrm{~N}\right]$ with a variable intermotif spacing of 15 to approximately 50 amino acids (Dunwell et al., 2001).

To find homologs of the cupin-like protein Cs033090 from C. sativus we collected AA sequences possessing the same conserved domain (Pfam 00190) as the candidate $\mathrm{HI}$ and aligned the two-motif sequences of all in silico putative homologs. We identified three monocupins and 13 bicupins with the same conserved domain. Four of the bicupins showed a high sequence identity to the candidate HI (Cs033090) within (Figure 1) and outside of (Figure 2) the conserved motifs. The highest similarity was detected between Cs033090 and Cs078390, these proteins were $63 \%$ identical. Sequences of Cs033080 and Cs240840 shared only 60 and 38\% identity with the candidate HI (Cs033090). To determine whether the candidate $\mathrm{HI}$ and its putative homologs possess (3Z):(2E)-hexenal isomerase activity we cloned the corresponding cDNAs of four (unfortunately we were unable to clone the putative HI Cs387820) of the five candidates and expressed their recombinant protein in E. coli. The purified recombinant protein of the initial candidate Cs033090 indeed possessed isomerase activity (from hereon called CsHI-1), as did the recombinant protein of the nearest homolog (Cs078390; now called CsHI-2) (Figure 3). Activity assays with both other homologs (Cs033080 and Cs240840; from hereon called CsHIlike 1 and CsHI-like 2, respectively) showed conversion rates from $Z$-3-hexenal to $E$-2-hexenal that did not differ from controls (Figure 3).

\section{Determination of Kinetic Parameters of the Active Hls}

The determination of kinetic parameters of the recombinant proteins $\mathrm{rCsHI}-1$ and $\mathrm{rCsHI}-2$ for $Z$-3-hexenal revealed that $\mathrm{K}_{\mathrm{m}}$ values of both recombinant enzymes were comparable ( $\mathrm{rCsHI}$ $1,0.6 \pm 1.3 \mathrm{mM}^{-1}$; rCsHI-2, $0.2 \pm 0.05 \mathrm{mM}^{-1}$ ). However, the turnover rate $\left(\mathrm{K}_{\text {cat }}\right)$ of rCsHI-1 was 90 -times higher than that of rCsHI-2 $\left(638 \pm 134 \mathrm{~s}^{-1}\right.$ and $\left.7.6 \pm 1.6 \mathrm{~s}^{-1} \mathrm{mM}^{-1}\right)$ leading to a 30 -fold higher $\mathrm{K}_{\text {cat }} / \mathrm{K}_{\mathrm{m}}$ ratio.

\section{Transient Expression of CsHls in N. benthaminana Changes the GLV Profile of Plants}

Plants produce considerable amounts of GLVs as a response to biotic and abiotic stress (Scala et al., 2013a). In order to test how expression of a cucumber-derived HI might change the GLV profile of plants that possess no substantial HI-activity by themselves we transiently expressed the four HI homologs in $N$. benthamiana and determined the GLV profile of infiltrated leaves after mechanical damage. Headspace of treated leaf disks was collected immediately after wounding for a period of $10 \mathrm{~min}$. Within this timeframe plants release mainly aldehydes and alcohols (Fall et al., 1999). While wounded leaf disks of plants expressing CsHI-1 and CsHI-2 emitted almost exclusively E-2GLVs (86 and 90\%, respectively) expression of CsHI-like 1 and 2 did not cause a significant increase in E-2-GLV levels compared to control treatments (Figure 4).

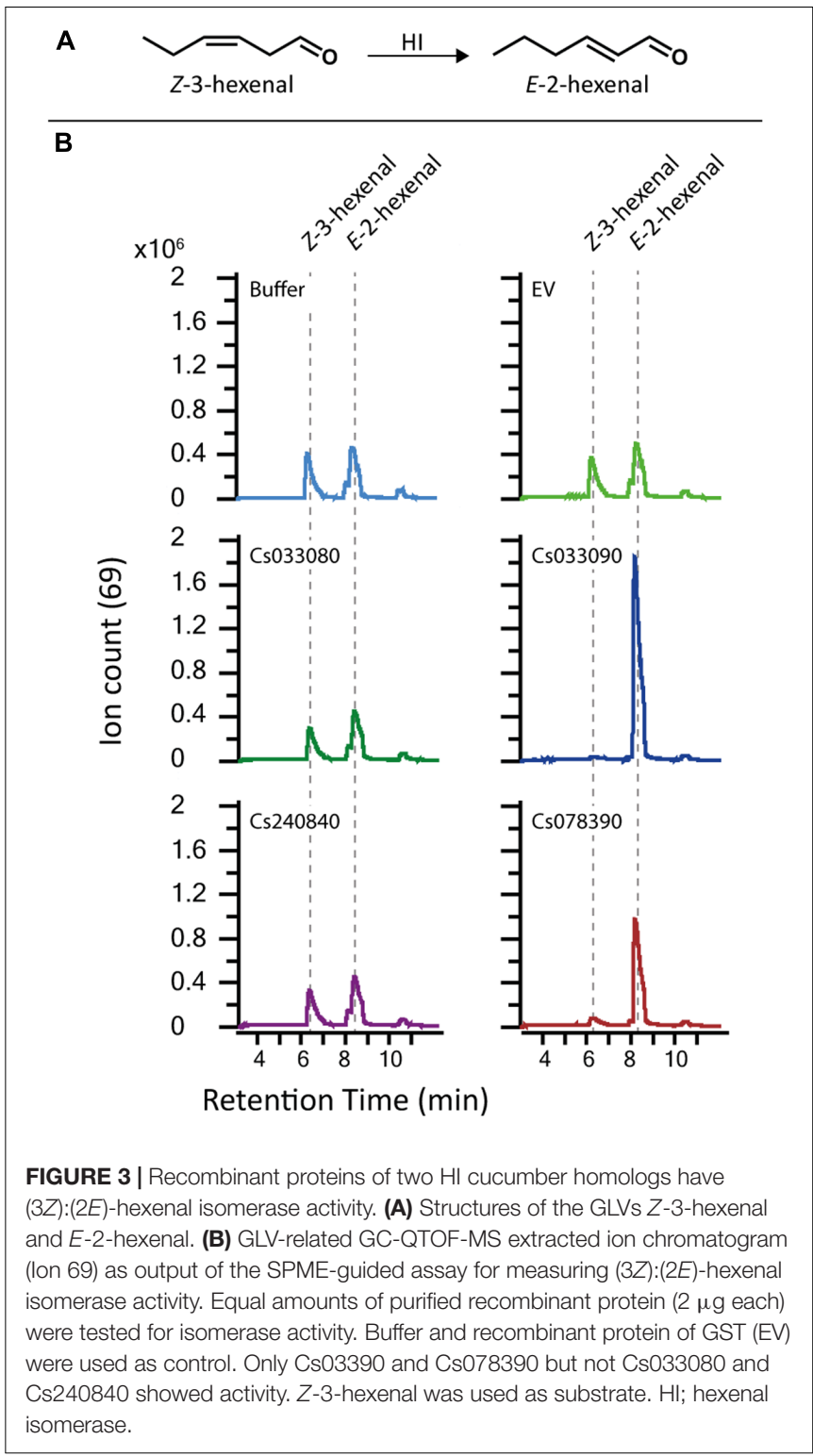

\section{HI Homologs Have Different Patterns of Expression}

To determine whether the four $\mathrm{HI}$ homologs exhibit tissue specific transcript levels we collected plant tissue from leaves, petioles, tendrils, and fruits (Figure 5A). While CsHI-1 (Cs033090) was specifically expressed in cucumber fruits, HI2 (Cs078390) was expressed in both, reproductive (fruits) and vegetative (leaves) tissue (Figure 5B). Interestingly, expression of both HIs was stronger in the flesh than in the skin of the fruit. This clear distinction between flesh and skin in HI transcript levels was not detectable for CsHI-like 1 (Cs033080) which was only expressed in cucumber fruits. We did not observe a clear tissue-specific expression pattern for CsHI-like 2 (Cs240840; Figure 5B).

Plants release high amounts of GLVs from their vegetative tissue upon wounding (Scala et al., 2013a). To test whether an 


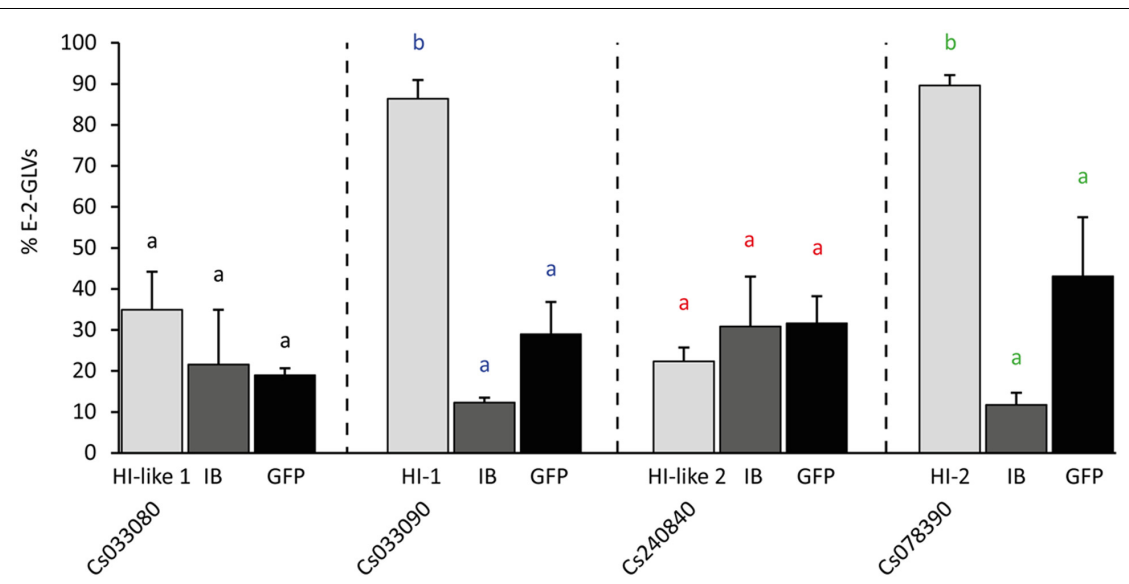

FIGURE 4 | Relative emission of E-2-GLVs in Nicotiana benthamiana leaves transiently expressing HI cucumber homologs. Two leaves per plant were infiltrated with Agrobacterium tumefaciens harboring one of the 35S-HI (hexenal isomerase) constructs or a 35S-GFP (GFP) construct or only the infiltration buffer (IB). From the equally treated areas of the two leaves per plant, leaf disks were punched out and artificially wounded. GLV emission (Z-3-hexenal, Z-3-hexenol, E-2-hexenal, and $E$-2-hexenol) of the two leaf disks was measured immediately after wounding and the percentage of $E$-2-GLVs was calculated. Statistics were done for each construct separately compared to infiltration buffer and GFP (letters with same color): different letters indicate significant differences between the treatments (univariate ANOVA, Cs033080: $F_{2,6}=0.82, p=0.48$; Cs033090: $F_{2,6}=54.07, p<0.001$; Cs240840: $F_{2,6}=0.39, p=0.69 ;$ Cs078390: $F_{2,6}=20.74$, $p<0.001$, followed by a Scheffé post hoc test).

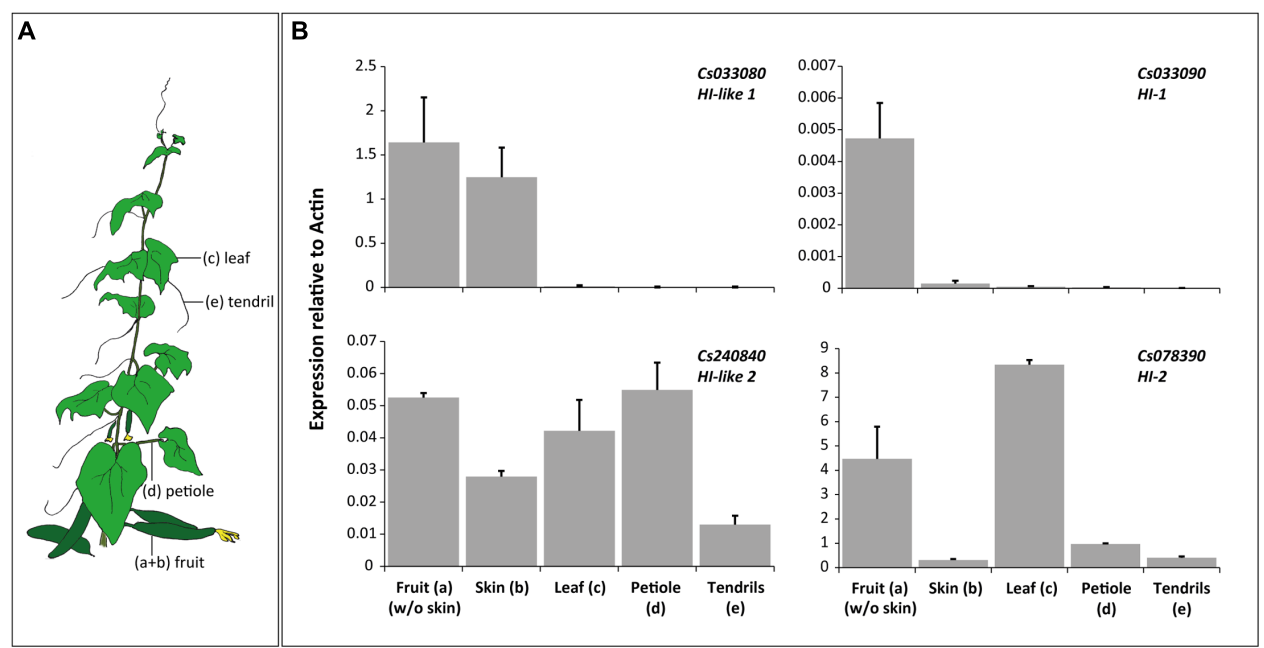

FIGURE 5 | Transcript abundance of HIs in different tissues of 9 week old cucumber plants. (A) Drawing of a cucumber plant illustrating which plant tissues were used for qRT-PCR. (B) Mean (+SEM) relative transcript abundance of the four Hls in peeled fruits (a), their skin (b), leaves (c), petioles of the same leaves (d) and tendrils (e).

increase in GLVs coincides with an increase in transcript levels of $H I-2$, which is expressed in leaves (Figure 5B), we harvested leaves from non-wounded and mechanically wounded cucumber plants. CsHI-2 transcript levels slightly increased $30 \mathrm{~min}$ after the treatment and stayed on this slightly elevated level the following $5 \mathrm{~h}$ (Figure 6).

\section{(Z,Z)-3,6-Nonadienal Can Be Used As Substrate by Both Hexenal Isomerases}

HI-1 has initially been purified from cucumber fruits. Also, transcript analysis revealed that this $\mathrm{HI}$ is solely expressed in the flesh of cucumbers. However, fruits contain only small amounts of E-2-hexenal while other E-2-alkenals, including E-2nonenal and $(E, Z)-2,6$-nonadienal have been detected in much higher quantities in this tissue (Wei et al., 2016). Since $(Z, Z)$ 3,6-nonadienal has been shown to serve as substrate for a red bell pepper HI (Kunishima et al., 2016) we tested whether this was also the case for the two active cucumber HIs. Indeed, recombinant proteins of both $\mathrm{HI}-1$ and $\mathrm{HI}-2$ were able to convert (Z,Z)-3,6-nonadienal to (E,Z)-2,6-nonadienal (Figure 7). These results indicate that $Z$-3-alkenals with different chain length and quantities of double bonds can be used as substrate by CsHI-1 and CsHI-2. 


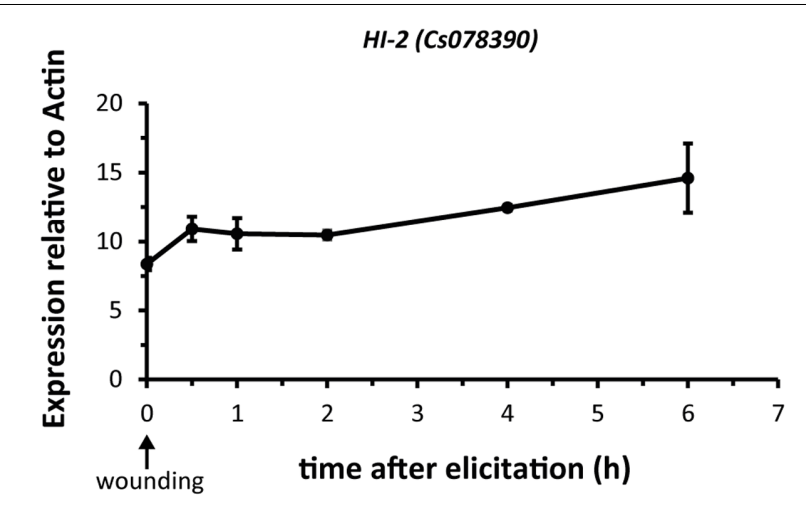

FIGURE 6 | Wound-inducibility of $H$ I-2 in cucumber leaves. Mean ( \pm SEM) expression of $\mathrm{HI}-2$ relative to actin. The first fully expanded leaf was harvested from un-wounded $(\mathrm{O} h$ ) and mechanically wounded 2-weeks old cucumber plants. Individual leaves from four independent plants per time point $(n=4)$ were harvested at each indicated time after elicitation. The abundance of $\mathrm{HI}-2$ transcript was analyzed by qRT-PCR and normalized to a reference gene (actin).

\section{DISCUSSION}

E-2-hexenal is a commonly occurring compound in the volatile bouquet of stressed plants and plays an important role in transferring information to plants and insects either as a single molecule (Farag and Paré, 2002; James, 2005; Kessler et al., 2006) or within a complex volatile mixture (Allmann and Baldwin, 2010; Allmann et al., 2013). While most biosynthetic enzymes upstream of $E$-2-hexenal have been studied extensively (Scala et al., 2013a; Mwenda and Matsui, 2014; ul Hassan et al., 2015), detailed information about the enzyme responsible for the conversion from Z-3- to E-2-hexenal had, until recently (Kunishima et al., 2016), been largely missing. In this study we have successfully identified two (3Z):(2E)hexenal isomerases (HIs) from cucumber fruits with different catalytic efficiencies for $Z$-3-hexenal. These hexenal isomerases were also able to convert $(Z, Z)-3,6$-nonadienal to $(E, Z)-2,6$ nonadienal, the latter representing the main flavor volatile of cucumber fruits (Huang et al., 2009). Overexpression of those HIs drastically changed the GLV profile of $N$. benthamiana plants.

Recently an HI has also been identified from bell pepper fruits and Z-3- to E-2-hexenal converting activity was confirmed by heterologous expression of a bell pepper HI and orthologous HIs of other plant species. Through point mutations of single amino acids H54, K60 and Y128, which led to a loss-of-function of recombinant protein of the bell pepper HI, Kunishima et al. (2016) identified a putative catalytic site (catalytic HKY) which was considered as an important prerequisite for the enzymatic function of HIs. The presence or absence of this catalytic HKY was subsequently used to identify putative plant HIs with or without Z-3- to E-2-hexenal converting activity and they were referred to as HIs and HI-like proteins, respectively. In this way three putative HIs and one HI-like protein from cucumber were identified by Kunishima et al. (2016).
However, while we identified the same 4 sequences in cucumber (Figures 1, 2), heterologous expression of these proteins revealed that only two of the three putative HIs with a catalytic HKY possessed HI-activity (Figures 3, 4). The third putative HI (Cs033080) was unable to convert Z-3- to E-2-hexenal, also when transiently overexpressed in $N$. benthamiana (Figure 4) and we thus referred to it as CsHI-like 1 . The fact that this protein is unable to convert $Z$-3-hexenal to its $E$-2-isomer is rather surprising, since Kunishima et al. (2016) reported that recombinant protein of this putative HI possessed $(3 Z):(2 E)$ hexenal isomerase activity. The RefseqID that was given for the cucumber HI tested for isomerase activity (XP_011651276.1) matches with the sequence of our CsHI-like 1 (Cs033080). However, the primers they used to clone the putative HI do not align to CsHI-like 1, but to CsHI-1 (Cs033090) which, also in our case, exhibits (3Z):(2E)-hexenal isomerase activity. We thus believe that CsHI-1 (Cs033090) instead of CsHIlike 1 (Cs033080) was cloned and heterologously expressed by the Japanese group. However, the question remains, why does CsHI-like 1 (Cs033080) show no activity although it possesses the catalytic HKY? Seed storage globulins are bicupins which are very closely related to the HIs. These proteins have lost their enzymatic activity most likely by losing three of the four metal-binding $\mathrm{H}$ and $\mathrm{E}$ residues in both of the two domains (Dunwell et al., 2004; Figure 1). Interestingly this loss of metalbinding residues did not lead to a loss of enzymatic activity for the two active HIs (Cs033090 and Cs078390; Figures 1, 3, 4). Further research will reveal whether other parts within or outside of the two motif sequence are equally important for maintaining enzymatic activity, whether CsHI-like 1 (Cs033080) might be active toward other, structurally related compounds or whether other changes in the sequence, e.g., the C-terminal extension (Figure 2), might have led to an inactivation of this protein.

Affinity tags are helpful tools to purify recombinant protein. However, they can also affect the biochemical properties of the target protein leading to, amongst others, inhibition or alteration of enzyme activity (Arnau et al., 2006; Costa et al., 2014). For our activity assay we used recombinant protein of which the GST-tag had not been removed prior to analysis. This might have altered the interaction between enzyme and substrate and thus might have influenced the outcome of the kinetic parameters. Although we cannot fully exclude this possibility, it is rather unlikely that the GST-fusion had a considerable effect on enzyme activity; recombinant protein of HIs from several plant species of which the His-tag had been removed prior to analysis resulted in very similar kinetic parameters (Table 2) ranging, e.g., from 0.2 to $1.78 \mathrm{mM}$ for $\mathrm{K}_{\mathrm{m}}$ values and from 27.7 to $521 \mathrm{~s}^{-1}$ for $\mathrm{K}_{\text {cat }}$ values (Kunishima et al., 2016).

Cucumber possesses 23 different LOX genes (Huang et al., 2009) which are divided into type 1 (9-LOX) or type 2 (13LOX) LOXs (Yang et al., 2012). This notable expansion of LOXs in the cucumber genome and the fact that cucumber has two tandem HPL genes (Huang et al., 2009) that can cleave both, 9- and 13-HPOs (Matsui et al., 2000; Wan et al., 2013), suggests that 9- and 13-HPL cleavage products play an 


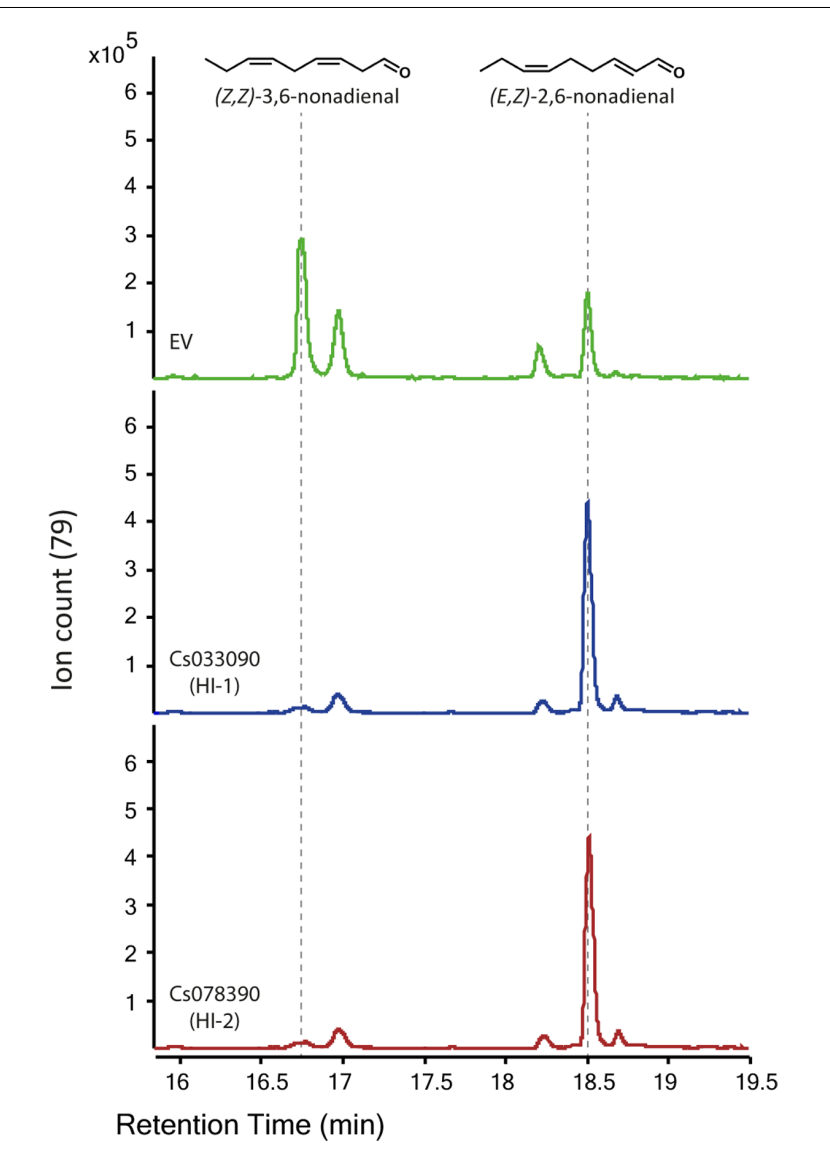

FIGURE 7 | Recombinant proteins of the two active Hls from cucumber can also use (Z,Z)-3,6-nonadienal as substrate. GLV-related GC-QTOF-MS extracted ion chromatogram (Ion 79) as output of the SPME-guided assay for measuring (3Z):(2E)-enal isomerase activity. Equal amounts of purified recombinant protein ( $2 \mu \mathrm{g}$ each) of the two active HIs (Cs033090 and Cs078390) were tested. Recombinant protein of GST (EV) was used as control. (Z,Z)-3,6-nonadienal was used as substrate.

important role in physiological and/or environmentally regulated processes. The main HPL-cleavage products in cucumber plants are the C9-aldehydes, $Z$-3-nonenal and (Z,Z)-3,6-nonadienal, which are formed from linoleic acid and $\alpha$-linolenic acid, respectively, and the C6-aldehyde, Z-3-hexenal (Matsui et al., $2000)$. However, due to the high HI-activity in cucumber these $Z$-3-aldehydes can be quickly converted to its E-2-isomers (Matsui et al., 2006). By testing the substrate specificity of partially purified HI from cucumber Phillips et al. (1979) revealed that the enzyme was able to convert $Z$-3-aldehydes with different chain lengths but showed highest efficiencies with $Z$-3-hexenal and Z-3-nonenal. Here we have shown that also $(Z, Z)-3,6$-nonadienal can be used as substrate by both HIs to form $(E, Z)$-2,6-nonadienal (Figure 7). Interestingly, $(E, Z)$ 2,6-nonadienal was detected in high levels in the reproductive tissues of cucumber, while E-2-hexenal, although ubiquitously present in all tested tissues, was mainly produced in the vegetative tissues, including leaves and roots (Wei et al., 2016). It is thus likely that CsHI-1 (Cs033090), which is
TABLE 2 | Kinetic parameters of recombinant cucumber (3Z):(2E)-hexenal isomerases $^{a}$

\begin{tabular}{cccc}
\hline & $\mathbf{K}_{\mathbf{c a t}}\left(\mathbf{s}^{-\mathbf{1}}\right)$ & $\mathbf{K}_{\mathbf{m}}(\mathbf{m M})$ & $\mathbf{K}_{\mathbf{c a t}} / \mathbf{K}_{\mathbf{m}}\left(\mathbf{s}^{\mathbf{- 1}} \mathbf{\mathbf { m M } ^ { - \mathbf { 1 } } )}\right.$ \\
\hline $\mathrm{H}-1$ & $683 \pm 134$ & $0.6 \pm 0.13$ & $1129 \pm 223$ \\
$\mathrm{H}-2$ & $7.6 \pm 1.6$ & $0.2 \pm 0.05$ & $37.7 \pm 2.1$ \\
\hline
\end{tabular}

a-3-hexenal has been used as substrate.

specifically expressed in the flesh of cucumber fruits, is mainly responsible for the rearrangement of the 9-HPL cleavage product from $\alpha$-linolenic acid, $(Z, Z)-3,6$-nonadienal, whereas CsHI-2 (Cs078390), which is expressed in fruits and leaves, represents the main $\mathrm{HI}$ responsible for the conversion of $Z$-3-hexenal to E-2-hexenal.

While we have identified the enzyme responsible for the conversion from $Z$-3- to $E$-2-aldehydes the question remains what the main function of this increased conversion is for plants. Recent research revealed that an increased conversion from $Z$-3- to E-2-GLVs can be beneficial for herbivore attacked plants by attracting natural enemies of the herbivores (Allmann and Baldwin, 2010) and by deterring gravid female moths (Allmann et al., 2013). Our results show, in contrast to previous results from Kunishima et al. (2016), that wounding only slightly increased the transcript levels of the leaf-specific $H I$ 2 (Figure 6). Future research will reveal whether there is a tight correlation between the amount of damage applied to the plant and $\mathrm{HI}$ expression, whether herbivore-specific factors are needed to amplify the wound-induced increase in transcript levels, whether HIs are post-transcriptionally regulated or whether they are constitutively expressed in leaves. In any case, there are also other, not mutually contradictory, explanations why plants possess $(3 Z):(2 E)$-hexenal isomerases: one possibility is that plants produce E-2-aldehydes in their fruits and leaves as a protection against microbial invaders; C6- as well as C9-aldehydes have bactericidal (Nakamura and Hatanaka, 2002; Cho et al., 2004) and antifungal (Hamiltonkemp et al., 1992; Matsui et al., 2006) properties and although the current literature is not conclusive on whether E-2aldehydes are more effective than $Z$-3-aldehydes (Nakamura and Hatanaka, 2002; Kishimoto et al., 2005; Prost et al., 2005; Tajul et al., 2012) the presence of an $\alpha, \beta$-unsaturated carbonyl moiety in E-2-aldehydes and the resulting high reactivity with nucleophilic atoms (Alméras et al., 2003) might enhance the antimicrobial properties of these molecules. Interestingly, the presence of an $\alpha, \beta$-unsaturated carbonyl group was not essential for several C6- and C9-compounds to serve as fungicidal agent against Botrytis cinerea and Fusarium oxysporum (Matsui et al., 2006). Clearly, much more work is needed to understand the physiological function of HIs for plants and the role they might play in plantinsect and plant-pathogen interactions. The engineering and characterization of plants with either reduced or no HI-activity will help to unravel the main function of this enzyme in plants.

Hexenal isomerase is by far one of the less investigated enzymes of the GLV biosynthesis pathway. Our results will not only impact future research on plant-biotic interaction, but might 
lead to advances in applications as GLVs and their derivatives play pivotal roles in the food and aroma industry.

\section{AUTHOR CONTRIBUTIONS}

SA, ES, and RS conceived the study, SA, ES, HD, and LS performed experiments, SA, ES, and HD analyzed the data, SA wrote the manuscript, ES, RS, $\mathrm{HD}, \mathrm{MH}, \mathrm{CdK}$, and JvM read and commented on the manuscript.

\section{FUNDING}

This work was supported by NWO-ALW grants 821.02 .027 (ES) and 863.14.011 (SA).

\section{REFERENCES}

Allmann, S., and Baldwin, I. T. (2010). Insects betray themselves in nature to predators by rapid isomerization of green leaf volatiles. Science 329, 1075-1078. doi: 10.1126/science.1191634

Allmann, S., Spathe, A., Bisch-Knaden, S., Kallenbach, M., Reinecke, A., Sachse, S., et al. (2013). Feeding-induced rearrangement of green leaf volatiles reduces moth oviposition. Elife 2:e00421. doi: 10.7554/eLife.00421

Alméras, E., Stolz, S., Vollenweider, S., Reymond, P., Mène-Saffrané, L., and Farmer, E. E. (2003). Reactive electrophile species activate defense gene expression in Arabidopsis. Plant J. 34, 205-216. doi: 10.1046/j.1365-313X.2003. 01718.x

Ameye, M., Allmann, S., Verwaeren, J., Smagghe, G., Haesaert, G., Schuurink, R. C., et al. (2017). Green leaf volatile production by plants: a meta-analysis. New Phytol. doi: 10.1111/nph.14671 [Epub ahead of print].

Ameye, M., Audenaert, K., De Zutter, N., Steppe, K., Van Meulebroek, L., Vanhaecke, L., et al. (2015). Priming of wheat with the green leaf volatile Z3-hexenyl acetate enhances defense against Fusarium graminearum but boosts deoxynivalenol production. Plant Physiol. 167, 1671-1684. doi: 10.1104/pp.15. 00107

Arnau, J., Lauritzen, C., Petersen, G. E., and Pedersen, J. (2006). Current strategies for the use of affinity tags and tag removal for the purification of recombinant proteins. Protein Expr. Purif. 48, 1-13. doi: 10.1016/j.pep.2005.12.002

Baldwin, I. T. (2010). Plant volatiles. Curr. Biol. 20, R392-R397. doi: 10.1016/j.cub. 2010.02.052

Bate, N. J., Riley, J. C. M., Thompson, J. E., and Rothstein, S. J. (1998). Quantitative and qualitative differences in C6-volatile production from the lipoxygenase pathway in an alcohol dehydrogenase mutant of Arabidopsis thaliana. Physiol. Plant. 104, 97-104. doi: 10.1034/j.1399-3054.1998.1040113.x

Bate, N. J., and Rothstein, S. J. (1998). C-6-volatiles derived from the lipoxygenase pathway induce a subset of defense-related genes. Plant J. 16, 561-569. doi: 10.1046/j.1365-313x.1998.00324.x

Brodmann, J., Twele, R., Francke, W., Holzler, G., Zhang, Q. H., and Ayasse, M. (2008). Orchids mimic green-leaf volatiles to attract prey-hunting wasps for pollination. Curr. Biol. 18, 740-744. doi: 10.1016/j.cub.2008.04.040

Chen, H., McCaig, B. C., Melotto, M., He, S. Y., and Howe, G. A. (2004). Regulation of plant arginase by wounding, jasmonate, and the phytotoxin coronatine. J. Biol. Chem. 279, 45998-46007. doi: 10.1074/jbc.M407151200

Cho, E. J., Yuen, C. Y. L., Kang, B.-H., Ondzighi, C. A., Staehelin, L. A., and Christopher, D. A. (2011). Protein disulfide isomerase-2 of Arabidopsis mediates protein folding and localizes to both the secretory pathway and nucleus, where it interacts with maternal effect embryo arrest factor. Mol. Cells 32, 459-475. doi: 10.1007/s10059-011-0150-3

Cho, M. J., Buescher, R. W., Johnson, M., and Janes, M. (2004). Inactivation of pathogenic bacteria by cucumber volatiles (E,Z)-2,6-nonadienal and (E)-2nonenal. J. Food Prot. 67, 1014-1016. doi: 10.4315/0362-028X-67.5.1014

\section{ACKNOWLEDGMENTS}

We thank Pieter van Egmond for the drawing of the cucumber plant in Figure 5A, Michel de Vries for assistance in the lab, the company Ventos for the donation of (Z,Z)-3,6-nonadienol and Ludek Tikovsky, Harold Lemereis, and Fernando Inchauste Callahuara for taking care of the cucumber plants in the glasshouse.

\section{SUPPLEMENTARY MATERIAL}

The Supplementary Material for this article can be found online at: http://journal.frontiersin.org/article/10.3389/fpls.2017.01342/ full\#supplementary-material

Costa, S., Almeida, A., Castro, A., and Domingues, L. (2014). Fusion tags for protein solubility, purification and immunogenicity in Escherichia coli: the novel Fh8 system. Frontiers in Microbiology 5:63. doi: 10.3389/fmicb.2014.00063

Curtius, T., and Franzen, H. (1914). Über die chemischen Bestandteile grüner Pflanzen. Über die flüchtigen Bestandteile der Hainbuchenblätter. Justus Liebigs Ann. Chem. 404, 93-130. doi: 10.1002/jlac.19144040202

D’Auria, J. C., Pichersky, E., Schaub, A., Hansel, A., and Gershenzon, J. (2007). Characterization of a BAHD acyltransferase responsible for producing the green leaf volatile (Z)-3-hexen-1-yl acetate in Arabidopsis thaliana. Plant J. 49, 194-207. doi: 10.1111/j.1365-313X.2006.02946.x

Dhonukshe, P., Huang, F., Galvan-Ampudia, C. S., Mahonen, A. P., KleineVehn, J., Xu, J. A., et al. (2010). Plasma membrane-bound AGC3 kinases phosphorylate PIN auxin carriers at TPRXS(N/S) motifs to direct apical PIN recycling. Development 137, 3245-3255. doi: 10.1242/dev.052456

Dunwell, J. M., Culham, A., Carter, C. E., Sosa-Aguirre, C. R., and Goodenough, P. W. (2001). Evolution of functional diversity in the cupin superfamily. Trends Biochem. Sci. 26, 740-746. doi: 10.1016/S0968-0004(01)01981-8

Dunwell, J. M., Purvis, A., and Khuri, S. (2004). Cupins: the most functionally diverse protein superfamily? Phytochemistry 65, 7-17. doi: 10.1016/j.phytochem.2003.08.016

Engelberth, J., Alborn, H. T., Schmelz, E. A., and Tumlinson, J. H. (2004). Airborne signals prime plants against insect herbivore attack. Proc. Natl. Acad. Sci. U.S.A. 101, 1781-1785. doi: 10.1073/pnas.0308037100

Engelberth, J., Contreras, C. F., Dalvi, C., Li, T., and Engelberth, M. (2013). Early transcriptome analyses of Z-3-Hexenol-treated Zea mays revealed distinct transcriptional networks and anti-herbivore defense potential of green leaf volatiles. PLoS ONE 8:e77465. doi: 10.1371/journal.pone.0077465

Fall, R., Karl, T., Hansel, A., Jordan, A., and Lindinger, W. (1999). Volatile organic compounds emitted after leaf wounding: on-line analysis by proton-transferreaction mass spectrometry. J. Geophys. Res. 104, 15963-15974. doi: 10.1029/ 1999JD900144

Farag, M. A., and Paré, P. W. (2002). C6-Green leaf volatiles trigger local and systemic VOC emissions in tomato. Phytochemistry 61, 545-554. doi: 10.1016/ S0031-9422(02)00240-6

Galliard, T., Phillips, D. R., and Reynolds, J. (1976). The formation of cis3-nonenal, trans-2-nonenal and hexanal from linoleic acid hydroperoxide isomers by a hydroperoxide cleavage enzyme system in cucumber (Cucumis sativus) fruits. Biochim. Biophys. Acta 441, 181-192. doi: 10.1016/0005-2760(76) 90161-2

Halitschke, R., Stenberg, J. A., Kessler, D., Kessler, A., and Baldwin, I. T. (2008). Shared signals - 'alarm calls' from plants increase apparency to herbivores and their enemies in nature. Ecol. Lett. 11, 24-34.

Halitschke, R., Ziegler, J., Keinanen, M., and Baldwin, I. T. (2004). Silencing of hydroperoxide lyase and allene oxide synthase reveals substrate and defense signaling crosstalk in Nicotiana attenuata. Plant J. 40, 35-46. doi: 10.1111/j. 1365-313X.2004.02185.x 
Hamiltonkemp, T. R., Mccracken, C. T., Loughrin, J. H., Andersen, R. A., and Hildebrand, D. F. (1992). Effects of some natural volatile compounds on the pathogenic fungi Alternaria-Alternata and Botrytis-Cinerea. J. Chem. Ecol. 18, 1083-1091. doi: 10.1007/BF00980064

Hatanaka, A., and Harada, T. (1973). Formation of cis-3-hexenal, trans-2hexenal and cis-3-hexenol in macerated Thea sinensis leaves. Phytochemistry 12, 2341-2346. doi: 10.1016/0031-9422(73)80435-2

Hatanaka, A., Kajiwara, T., and Sekiya, J. (1987). Biosynthetic pathway for C6aldehydes formation from linolenic acid in green leaves. Chem. Phys. Lipids 44, 341-361. doi: 10.1016/0009-3084(87)90057-0

Hatanaka, A., Kajiwara, T., Sekiya, J., and Hirata, H. (1976). Biosynthetic-pathway of leaf aldehyde in farfugium-japonicum kitamura leaves. Agric. Biol. Chem. 40, 2177-2180. doi: 10.1271/bbb1961.40.2177

Heil, M. (2014). Herbivore-induced plant volatiles: targets, perception and unanswered questions. New Phytol. 204, 297-306. doi: 10.1111/nph.12977

Huang, S., Li, R., Zhang, Z., Li, L., Gu, X., Fan, W., et al. (2009). The genome of the cucumber, Cucumis sativus L. Nat. Genet. 41, 1275-1281. doi: 10.1038/ng.475

James, D. G. (2005). Further field evaluation of synthetic herbivore-induced plan volatiles as attractants for beneficial insects. J. Chem. Ecol. 31, 481-495. doi: 10.1007/s10886-005-2020-y

Karimi, M., De Meyer, B., and Hilson, P. (2005). Modular cloning in plant cells. Trends Plant Sci. 10, 103-105. doi: 10.1016/j.tplants.2005.01.008

Kessler, A., Halitschke, R., Diezel, C., and Baldwin, I. T. (2006). Priming of plant defense responses in nature by airborne signaling between Artemisia tridentata and Nicotiana attenuata. Oecologia 148, 280-292. doi: 10.1007/s00442-0060365-8

Kishimoto, K., Matsui, K., Ozawa, R., and Takabayashi, J. (2005). Volatile C6aldehydes and Allo-ocimene activate defense genes and induce resistance against Botrytis cinerea in Arabidopsis thaliana. Plant Cell Physiol. 46, 1093-1102. doi: $10.1093 / \mathrm{pcp} / \mathrm{pci} 122$

Kishimoto, K., Matsui, K., Ozawa, R., and Takabayashi, J. (2008). Direct fungicidal activities of C6-aldehydes are important constituents for defense responses in Arabidopsis against Botrytis cinerea. Phytochemistry 69, 2127-2132. doi: 10.1016/j.phytochem.2008.04.023

Kost, C., and Heil, M. (2006). Herbivore-induced plant volatiles induce an indirect defence in neighbouring plants. J. Ecol. 94, 619-628. doi: 10.1111/j.1365-2745. 2006.01120.x

Kunishima, M., Yamauchi, Y., Mizutani, M., Kuse, M., Takikawa, H., and Sugimoto, Y. (2016). Identification of (Z)-3:(E)-2-Hexenal isomerases essential to the production of the leaf aldehyde in plants. J. Biol. Chem. 291, 14023-14033. doi: $10.1074 /$ jbc.M116.726687

Li, P. Y., Zhu, J. W., and Qin, Y. C. (2012). Enhanced attraction of Plutella xylostella (Lepidoptera: Plutellidae) to pheromone-baited traps with the addition of green leaf volatiles. J. Econ. Entomol. 105, 1149-1156. doi: 10.1603/ec11109

Li, T., Cofer, T., Engelberth, M., and Engelberth, J. (2016). Defense priming and jasmonates: a role for free fatty acids in insect elicitor-induced long distance signaling. Plants 5, 5. doi: 10.3390/plants5010005

Maffei, M. E., Gertsch, J., and Appendino, G. (2011). Plant volatiles: production, function and pharmacology. Nat. Prod. Rep. 28, 1359-1380. doi: 10.1039/ clnp00021g

Matsui, K., and Koeduka, T. (2016). "Green leaf volatiles in plant signaling and response," in Lipids in Plant and Algae Development, eds Y. Nakamura and Y. Li-Beisson (Cham: Springer International Publishing), 427-443. doi: 10.1007/ 978-3-319-25979-6_17

Matsui, K., Minami, A., Hornung, E., Shibata, H., Kishimoto, K., Ahnert, V., et al. (2006). Biosynthesis of fatty acid derived aldehydes is induced upon mechanical wounding and its products show fungicidal activities in cucumber. Phytochemistry 67, 649-657. doi: 10.1016/j.phytochem.2006. 01.006

Matsui, K., Sugimoto, K., Mano, J., Ozawa, R., and Takabayashi, J. (2012). Differential metabolisms of green leaf volatiles in injured and intact parts of a wounded leaf meet distinct ecophysiological requirements. PLOS ONE 7:e36433. doi: 10.1371/journal.pone.0036433

Matsui, K., Ujita, C., Fujimoto, S.-H., Wilkinson, J., Hiatt, B., Knauf, V., et al. (2000). Fatty acid 9- and 13-hydroperoxide lyases from cucumber1. FEBS Lett. 481, 183-188. doi: 10.1016/S0014-5793(00)01997-9

Mwenda, C. M., and Matsui, K. (2014). The importance of lipoxygenase control in the production of green leaf volatiles by lipase-dependent and independent pathways. Plant Biotechnol. 31, 445-452. doi: 10.5511/plantbiotechnology.14. 0924a

Nakamura, S., and Hatanaka, A. (2002). Green-leaf-derived C6-aroma compounds with potent antibacterial action that act on both gram-negative and grampositive bacteria. J. Agric. Food Chem. 50, 7639-7644. doi: 10.1021/Jf02 $5808 \mathrm{c}$

Nakashima, A., von Reuss, S. H., Tasaka, H., Nomura, M., Mochizuki, S., Iijima, Y., et al. (2013). Traumatin- and dinortraumatin-containing galactolipids in Arabidopsis: their formation in tissue-disrupted leaves as counterparts of green leaf volatiles. J. Biol. Chem. 288, 26078-26088. doi: 10.1074/jbc.M113.48 7959

Noordermeer, M. A., Veldink, G. A., and Vliegenthart, J. F. G. (1999). Alfalfa contains substantial 9-hydroperoxide lyase activity and a $3 \mathrm{Z}$ : 2E-enal isomerase. FEBS Lett. 443, 201-204. doi: 10.1016/S0014-5793(98)01706-2

Phillips, D. R., Matthew, J. A., Reynolds, J., and Fenwick, G. R. (1979). Partial purification and properties of a cis-3: trans-2-enal isomerase from cucumber fruit. Phytochemistry 18, 401-404. doi: 10.1016/S0031-9422(00)81874-9

Pickett, J. A., and Khan, Z. R. (2016). Plant volatile-mediated signalling and its application in agriculture: successes and challenges. New Phytol. 212, 856-870. doi: 10.1111/nph.14274

Prost, I., Dhondt, S., Rothe, G., Vicente, J., Rodriguez, M. J., Kift, N., et al. (2005). Evaluation of the antimicrobial activities of plant oxylipins supports their involvement in defense against pathogens. Plant Physiol. 139, 1902-1913. doi: 10.1104/pp.105.066274

Sasaki, K., Urabe, D., Arai, H., Arita, M., and Inoue, M. (2011). Total synthesis and bioactivities of two proposed structures of maresin. Chem. Asian J. 6, 534-543. doi: 10.1002/asia.201000494

Scala, A., Allmann, S., Mirabella, R., Haring, M., and Schuurink, R. (2013a). Green leaf volatiles: a plant's multifunctional weapon against herbivores and pathogens. Int. J. Mol. Sci. 14, 17781-17811. doi: 10.3390/ijms14091 7781

Scala, A., Mirabella, R., Mugo, C., Matsui, K., Haring, M. A., and Schuurink, R. C. (2013b). E-2-hexenal promotes susceptibility to Pseudomonas syringae by activating jasmonic acid pathways in Arabidopsis. Front. Plant Sci. 4:74. doi: 10.3389/fpls.2013.00074

Shevchenko, A., Wilm, M., Vorm, O., and Mann, M. (1996). Mass spectrometric sequencing of proteins from silver-stained polyacrylamide gels. Anal. Chem. 68, 850-858. doi: 10.1021/ac950914h

Shi, J., Wang, J., Li, R., Li, D., Xu, F., Sun, Q., et al. (2015). Expression patterns of genes encoding plasma membrane aquaporins during fruit development in cucumber (Cucumis sativus L.). Plant Physiol. Biochem. 96, 329-336. doi: 10.1016/j.plaphy.2015.08.018

Shiojiri, K., Kishimoto, K., Ozawa, R., Kugimiya, S., Urashimo, S., Arimura, G., et al. (2006). Changing green leaf volatile biosynthesis in plants: an approach for improving plant resistance against both herbivores and pathogens. Proc. Natl. Acad. Sci. U.S.A. 103, 16672-16676. doi: 10.1073/pnas.0607780103

Tajul, M. I., Motoyama, T., Hatanaka, A., Sariah, M., and Osada, H. (2012). Green-odour compounds have antifungal activity against the rice blast fungus Magnaporthe oryzae. Eur. J. Plant Pathol. 132, 91-100. doi: 10.1007/s10658011-9851-x

Takamura, H., and Gardner, H. W. (1996). Oxygenation of (3Z)-alkenal to (2E)4-hydroxy-2-alkenal in soybean seed (Glycine max L). Biochim. Biophys. Acta 1303, 83-91. doi: 10.1016/0005-2760(96)00076-8

Turlings, T. C. J., Tumlinson, J. H., Heath, R. R., Proveaux, A. T., and Doolittle, R. E. (1991). Isolation and identification of allelochemicals that attract the larval parasitoid,Cotesia marginiventris (Cresson), to the microhabitat of one of its hosts. J. Chem. Ecol. 17, 2235-2251. doi: 10.1007/bf00988004

ul Hassan, M. N., Zainal, Z., and Ismail, I. (2015). Green leaf volatiles: biosynthesis, biological functions and their applications in biotechnology. Plant Biotechnol. J. 13, 727-739. doi: 10.1111/pbi.12368

Vancanneyt, G., Sanz, C., Farmaki, T., Paneque, M., Ortego, F., Castanera, P., et al. (2001). Hydroperoxide lyase depletion in transgenic potato plants leads to an increase in aphid performance. Proc. Natl. Acad. Sci. U.S.A. 98, 8139-8144. doi: 10.1073/pnas.141079498

Voinnet, O., Rivas, S., Mestre, P., and Baulcombe, D. (2003). Retracted: an enhanced transient expression system in plants based on suppression of gene silencing by the p19 protein of tomato bushy stunt virus. Plant J. 33, 949-956. doi: 10.1046/j.1365-313X.2003.01676.x 
Wan, X.-H., Chen, S.-X., Wang, C.-Y., Zhang, R.-R., Cheng, S.-Q., Meng, H.-W., et al. (2013). Isolation, expression, and characterization of a hydroperoxide lyase gene from cucumber. Int. J. Mol. Sci. 14, 22082. doi: 10.3390/ijms141122082

Wei, G., Tian, P., Zhang, F., Qin, H., Miao, H., Chen, Q., et al. (2016). Integrative analyses of non-targeted volatile profiling and transcriptome data provide molecular insight into VOC diversity in cucumber plants (Cucumis sativus L.). Plant Physiol. 172, 603-618. doi: 10.1104/pp.16.01051

Yang, X.-Y., Jiang, W.-J., and Yu, H.-J. (2012). The expression profiling of the lipoxygenase (LOX) family genes during fruit development, abiotic stress and hormonal treatments in cucumber (Cucumis sativus L.). Int. J. Mol. Sci. 13:2481. doi: $10.3390 / \mathrm{ijms} 13022481$
Conflict of Interest Statement: The authors declare that the research was conducted in the absence of any commercial or financial relationships that could be construed as a potential conflict of interest.

Copyright (๑) 2017 Spyropoulou, Dekker, Steemers, van Maarseveen, de Koster, Haring, Schuurink and Allmann. This is an open-access article distributed under the terms of the Creative Commons Attribution License (CC BY). The use, distribution or reproduction in other forums is permitted, provided the original author(s) or licensor are credited and that the original publication in this journal is cited, in accordance with accepted academic practice. No use, distribution or reproduction is permitted which does not comply with these terms. 